\title{
Ação cultural com mídias sociais: análise do Facebook do Sistema Estadual de Bibliotecas Públicas de São Paulo (SisEB)
}

\section{Cultural action with social media: analysis of the State System of Public Libraries of São Paulo (SisEB) Facebook}

\author{
Andrea Pereira Santos ${ }^{1}$, Vanessa Guimarães Nascimento ${ }^{2}$ \\ ${ }^{1}$ Universidade Federal de Goiás (UFGO), Goiânia, GO, Brasil. ORCID: https://orcid.org/0000-0001-5410-5500 \\ 2 Universidade Federal de Goiás (UFGO), Goiânia, GO, Brasil. ORCID: https://orcid.org/0000-0001-9419-7913
}

Autor para correspondência/Mail to: Andrea Pereira Santos, andreabiblio@ufg.br

Recebido/Submitted: 17 de setembro de 2020; Aceito/Approved: 24 de novembro de 2020

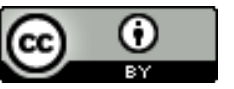

Copyright (c) 2021 Santos \& Nascimento. Todo o conteúdo da Revista (incluindo-se instruções, política editorial e modelos) está sob uma licença Creative Commons Atribuição 4.0 Internacional. Ao serem publicados por esta Revista, os artigos são de livre uso em ambientes educacionais, de pesquisa e não comerciais, com atribuição de autoria obrigatória. Mais informações em http://revistas.ufpr.br/atoz/about/submissions\#copyrightNotice.

\begin{abstract}
Resumo
Introdução: Considerando o cenário da comunicação a partir das mídias sociais, objetiva-se verificar como as bibliotecas têm utilizado essas mídias para interagir com seu público, tendo como objeto de estudo a página oficial do Facebook do Sistema Estadual de Bibliotecas Públicas de São Paulo (SisEB). Os principais aportes teóricos utilizados pela pesquisa levaram em conta o tema discutido no artigo. Sobre cibercultura e mídias sociais, embasando-se em autores como Lévy (2010), Lemos (2013) e Recuero (2010) e sobre ação cultural com base em Coelho (2001), Milanesi (2003) e Barros (2010). Método: A metodologia aplicada contemplou a análise documental. Junto à análise documental do Facebook do SisEB, foi realizada também a análise de conteúdo de acordo com Bardin (1977), a fim de verificar se os conteúdos publicados nessa rede estão relacionados à ação cultural. Resultados: Os resultados apontam primeiras inferências de que o SisEB publica mais conteúdos de caráter informativo e divulgação de suas atividades do que a promoção de ação cultural propriamente dita. Conclusão: Tais atividades podem contribuir para que as esferas da ação cultural, conforme Coelho (2001), se tornem realidade.
\end{abstract}

Palavras-chave: Mídias sociais; Biblioteca pública; Cibercultura; Ação cultural.

\begin{abstract}
Introduction: Considering the scenario of communication from social media, the objective is to verify how libraries have used these media to interact with their audience, having as object of study the official Facebook page of the State System of Public Libraries of São Paulo ( SisEB). The main theoretical contributions used by the research took into account the theme discussed in the article. About cyberculture and social media, based on authors such as Lévy (2010), Lemos (2013) and Recuero (2010) and cultural action based on Coelho (2001), Milanesi (2003) and Barros (2010). Method: The applied methodology included documentary analysis. Along with the documentary analysis of SisEB's Facebook, content analysis was also carried out, according to Bardin (1977), to verify whether the contents published in this network are related to cultural action. Results: The results point to the first inferences that SisEB publishes more informational content type and dissemination of its activities than the promotion of cultural action itself. Conclusion: Such activities can contribute to the spheres of cultural action, according to Coelho (2001), to become a reality.
\end{abstract}

Keywords: Social media; Public Libraries; Cyberculture; Cultural action.

\section{INTRODUÇÃO}

O desenvolvimento tecnológico tem possibilitado a implementação de novos dispositivos no cotidiano das pessoas, proporcionando outros hábitos sociais. As mídias sociais são um dos elementos que se configuram nesse contexto, pois têm se tornado um fenômeno com características que também têm modificado a dinâmica social, na qual emergem novas práticas culturais, diferentes modos de interação e compartilhamento de informação em rede.

A internet, de um modo geral, apresenta a possibilidade de uma convergência participativa por meio do engajamento entre diferentes pessoas conectadas à rede. Desse modo, essas ferramentas se tornaram aliadas ao desenvolvimento de diversas atividades, uma vez que permitem o compartilhamento de diversas ações protocoladas por pessoas e instituições nesse ambiente interacional.

A prestação de serviços pelas bibliotecas também é impactada nesse contexto, pois as ferramentas tecnológicas possibilitam a oportunidade de serem integradas tanto nas atividades de rotina dessas instituições, como para estabelecer interações com seus públicos em um ambiente virtual.

Tem sido comum a utilização das mídias sociais nas organizações para a divulgação de serviços e produtos e com isso acabam se conectando com mais clientes. As bibliotecas são instituições que também visam satisfazer as necessidades informacionais de seus públicos; então essas mídias podem ser úteis para disseminar informação tanto aos usuários reais, quanto aos potenciais, tendo em vista que a conexão por meio da internet transcende barreiras físicas. 
No entanto, no seio das atividades que são desenvolvidas pelas bibliotecas, destaca-se a multiplicidade de suas funções, uma vez que não está engessada à mera disponibilização de informações, pois sua essência como instituição cultural lhe atribui outros papéis que a tornam um verdadeiro organismo vivo.

É nessa dinâmica que evidenciamos as possibilidades que as mídias sociais proporcionam às bibliotecas, pois elas têm potencial de serem utilizadas para além da simples divulgação de horário de funcionamento, de serviços e produtos oferecidos. Essas mídias permitem que sejam desenvolvidas novas maneiras de conexão com o público, criando possibilidades inovadoras de comunicação que originam outros papéis sociais para estas instituições.

As bibliotecas têm, em sua natureza, uma importante função social, sendo difusoras de cultura por serem local de armazenamento, acesso e disseminação da informação. Com o contexto contemporâneo, essa missão é possível de ser efetivada de distintas maneiras das tradicionais, surgindo ainda outras ações aliadas ao uso das ferramentas tecnológicas de comunicação.

Para tanto, este trabalho tem como propósito responder ao seguinte questionamento: "Como as postagens no facebook do Sistema Estadual de Bibliotecas Públicas de São Paulo (SisEB) realizam a promoção de ação cultural junto aos seguidores?".

Para responder essa questão, propomos como objetivo geral investigar, por meio de uma análise de conteúdo, a utilização do Facebook pelo Sistema Estadual de Bibliotecas Públicas de São Paulo na promoção da ação cultural.

Como fundamentação teórica da pesquisa, foram utilizados os conceitos sobre cibercultura com base nos autores Levy (2010) e Lemos (2013); mídias sociais com embasamento em Telles (2011) e Recuero (2010) e sobre ação cultural com base nos conceitos propostos por Coelho (2001), Milanesi (2003) e Barros (2010).

A seguir serão apresentados os procedimentos metodológicos realizados para a elaboração deste artigo, seguido do desenvolvimento do trabalho que se divide em tópicos sobre a cibercultura, mídias sociais e bibliotecas, bibliotecas e ação cultural, análise dos resultados e, por fim, a apresentação das considerações finais sobre o estudo.

\section{PROCEDIMENTOS METODOLÓGICOS}

Trata-se de uma pesquisa fenomenológica, qualitativa, básica, exploratória e documental já que o principal foco foi a análise da página oficial do Facebook do SisEB.

Junto à pesquisa documental, foi aplicado o método de análise de conteúdo, conforme proposto por Bardin (1977), com o objetivo de verificar se os conteúdos das publicações efetuadas nessa rede promovem a ação cultural junto ao público.

A escolha do objeto fundamentou-se no fato dessa rede de bibliotecas ser referência na promoção de ações e projetos culturais em seus espaços físicos, tendo proposta diferenciada para bibliotecas de acesso público no Brasil, sendo efetiva, ainda, no uso de diferentes mídias sociais ${ }^{1}$, como Facebook e Youtube, apresentando-se, assim, como um objeto propício ao estudo empírico do trabalho.

A análise de conteúdo é uma técnica que tem como campo a "análise das comunicações" (Bardin, 1977, p. 31) e tem o intuito de:

[...] obter, por procedimentos sistemáticos e objectivos de descrição do conteúdo das mensagens, indicadores (quantitativos ou não) que permitam a inferência de conhecimentos relativos às condições de produção/recepção (variáveis inferidas) destas mensagens (Bardin, 1977, p. 42).

Levando-se em conta a pergunta central da presente pesquisa, a análise de conteúdo é efetiva, uma vez que possibilita ao analista realizar inferências sobre os "possíveis efeitos das mensagens" (Bardin, 1977, p. 39). Isto é, a partir desta técnica, o pesquisador pode verificar as consequências e influências de uma informação disponível em determinada mídia.

A análise da página foi categorizada de forma temática e foram analisados os significados das mensagens publicadas pelo SisEB. O método utilizado para a definição das categorias foi o de caixas, no qual elas são escolhidas antes de serem selecionadas as análises de registro (Bardin, 1977). Assim, as categorias foram previamente estabelecidas de acordo com o entendimento dos conceitos expostos pelos autores Coelho (2001), Milanesi (2003), Barros (2010), Freire (2011) e Cunha (2010) sobre ação cultural, o que possibilitou definir os seguintes elementos como categorias: diversidade social, cultura, liberdade, acessibilidade, criatividade e transformação social.

As análises de registro são frases, palavras e/ou expressões (Bardin, 1977). Nesse estudo, optou-se por selecionar frases e palavras, uma vez que foram analisados os textos contidos nas imagens, nas legendas e nas hashtags das

\footnotetext{
${ }^{1}$ Canal do youtube: https://www.youtube.com/user/SisEBSP Página do facebook: https://pt-br.facebook.com/sisebsp/
} 
postagens. Para realizar a análise de conteúdo categorizada, foram selecionadas cinco postagens no Facebook do SisEB, por meio da ferramenta netvizz, que compreenderam o período de 01 julho à 31 dezembro de 2017.

A partir da ferramenta netvizz, optou-se por selecionar as cinco publicações que obtiveram o maior número de curtidas no ínterim especificado e que, além disso, foram constatadas como possíveis hipóteses para o problema da pesquisa, uma vez que foram extraídas por meio de uma "leitura flutuante" que é a "pré-análise" realizada no material conforme definido por Bardin (1977, p. 96). Como foi escolhido o Facebook da instituição como objeto empírico, não seria possível analisar todas as publicações da página e, devido à extensão deste artigo, o recorte foi necessário.

Portanto, a análise compreendeu a elaboração de uma tabela única, categorizando as frases extraídas das cinco postagens em uma mesma tabela, uma vez que a análise tem o mesmo objetivo para as cinco publicações. Após a elaboração da tabela, procedeu-se com a análise dos resultados, retomando o embasamento teórico sobre a ação cultural, o problema central do trabalho e o objetivo previamente estabelecidos.

\section{SOBRE O SISTEMA SISEB}

O SisEB foi criado em 1984, por meio da Secretaria de Cultura do governo do Estado de São Paulo e integra bibliotecas públicas, municipais e comunitárias do Estado. O sistema tem como objetivo "estimular e apoiar as bibliotecas de acesso público do Estado na democratização da informação, do livro e da leitura" (Sistema Estadual de Bibliotecas Públicas de São Paulo, 2018), sendo composta atualmente por mais de 800 unidades, incluindo a Biblioteca de São Paulo (BSP) e a Biblioteca Parque Villa-Lobos (BVL).

O SisEB organiza anualmente o Seminário Internacional de Bibliotecas Públicas e Comunitárias (Seminário Biblioteca Viva) que ocorre em São Paulo e visa estimular que as bibliotecas públicas promovam espaços culturais atrativos à leitura e que se aproximem da comunidade por meio do acesso à informação (Sistema Estadual de Bibliotecas Públicas de São Paulo, 2018).

O Sistema possui um site oficial para integrar toda a rede e utiliza as seguintes mídias sociais: um canal no Youtube, uma página oficial no Facebook e um blog da Instituição, publicando nesses meios diversos conteúdos referentes aos serviços, produtos e ações desenvolvidas pelas bibliotecas que integra.

Por fim, o Facebook do SisEB possui até o momento 27.757 seguidores. Verificou-se que, diariamente, as publicações variam de três a quarto posts em média, tornando-se, portanto, o objeto escolhido para a aplicação do método de análise proposto neste estudo. As postagens, em sua maioria, são compostas por links, imagens acompanhadas de um texto e legendas, as quais buscam a interação com os seguidores por meio de perguntas, frases chamativas e figuras que ilustram o conteúdo dos textos.

\section{O MOVIMENTO SOCIAL DA CIBERCULTURA}

O movimento mediado pelas interações que ocorrem em ambiente virtual é o que se denomina por Ciberculturacite (Levy, 2010). Essa prática se desenvolve no ciberespaço, conceituado por Levy (2010, p. 94) como "o espaço de comunicação aberto pela interconexão mundial dos computadores e das memórias dos computadores", de modo que ele se configura em torno dos sistemas de comunicação eletrônicos que envolvem a codificação digital, o aspecto virtual da circulação de informação, a hipertextualidade e interatividade em tempo real. Esta dinâmica social, tendo como características as interações em ambiente online, interconexão universal, criação de comunidades virtuais e a inteligência coletiva é representado pela cibercultura a qual apresenta práticas culturais convergentes em novas possibilidades de comunicação em rede.

Lemos (2013, p. 90), define a cibercultura como:

uma estética social alimentada pelo que se pode chamar de tecnologias do ciberespeço (redes informáticas, realidade virtual, multimedia). A cibercultura forma-se, precisamente, da convergência entre o social e o tecnológico, sendo através da inclusão da socialidade na prática diária da tecnologia que ela adquire seus contornos mais nítidos.

Nesse sentido, observa-se que o momento contemporâneo marcado pela cibercultura desencadeia reconfigurações em diferentes âmbitos sociais como no econômico, no político e no cultural, uma vez que, com a evidência de novos modos de sociabilidade, criam-se diferentes maneiras de interação entre os indivíduos e nas estruturas sociais marcadas pela cultura eletrônica.

O movimento social da cibercultura promove mudanças em diferentes aspectos do cotidiano da sociedade, pois as técnicas disponíveis em cada contexto influenciam as formas de vida, uma vez que "as tecnologias tornam-se vetores de novas formas de agregação social" (Lemos, 2013, p. 16).

\footnotetext{
${ }^{2}$ Recuperado de https://www.facebook.com/sisebsp (2020, agosto 6)
} 
Para Levy (2010) um ponto importante merece destaque: os delineamentos possíveis com a cibercultura permitem uma comunicação em rede de alcance universal, mas agora não mais marcada pela unilateralidade do emissor, mas sim pela interatividade, interconexão em rede, diálogos simultâneos e produção de conteúdos manifestos pela heterogeneidade das fontes de informação e diferentes expressões da diversidade social.

Sanatella (2003) enfatiza que a produção desses meios interativos causam mudanças nos hábitos sociais, os quais cada indivíduo pode produzir e difundir seus próprios conteúdos. Esse ambiente de comunicação em rede tem-se efetivado no sentido de propiciar não só outras práticas comunicacionais, mas também diferentes encontros sociais e mobilização em grupo, tal como sera exposto acerca da ação cultural em bibliotecas. Nesse sentido, ocorre a reconfiguracao dos espacos tradicionais e da estrutura social, pois "as modificações sofridas nos meios revelam como a sociedade apropria-se dessas estruturas no sentido de ampliar a conversação, criando novas lógicas e processos de interação social" (Mainieri, 2016, p. 46).

\section{A CIBERCULTURA E AS COMUNIDADES VIRTUAIS}

As comunidades virtuais são fenômeno que tem emergido a partir da concepção da cibercultura. Conforme considera Castells (2010, p. 57), "a comunicação mediada por computadores gera uma gama enorme de comunidades virtuais". Com a efetivação da rede de computadores e o progresso da internet, as relações que ocorrem nesses ambientes têm se intensificado, criando agrupamentos entre indivíduos que interagem em uma espécie de comunidade.

Segundo Lévy e Lemos (2010), comunidade virtual refere-se a "um grupo de pessoas que estão em relação por intermédio do ciberespaço", considerando-se, por exemplo, os grupos de chats, blogs, Facebook, Twitter, que se comunicam nesses ambientes de acordo com assuntos e interesses comuns.

Com essa perspectiva, os autores consideram que essas comunidades virtuais podem ocorrer no ciberespaço de duas maneiras: "do tipo comunitário", quando se agregam com certa afinidade, algum vínculo afetivo e "compartilham um espaço telemático e simbólico" (Lévy \& Lemos, 2010, p. 102) e do tipo "não comunitária", quando não há uma coesão entre os membros do grupo, havendo apenas a troca de "informações e de experiências de caráter efêmero e desterritorializado" (Lévy \& Lemos, 2010, p. 103).

Para Sanatella (2003, p. 121), as comunidades virtuais são compostas por "grupos de pessoas globalmente conectadas na base de interesses e afinidades, em lugar de conexões acidentais ou geográficas". Nesse sentido, as comunidades virtuais se caracterizam como ponto chave no processo de ação cultural que será exposto a seguir, uma vez que envolve compartilhamento e interação em grupos, como ocorre no Facebook.

\section{MÍDIAS SOCIAIS E BIBLIOTECAS: ALGUMAS POSSIBILIDADES}

Nas práticas comunicacionais que se propagam no ambiente virtual, destacam-se as que ocorrem nas mídias sociais que se apresentam como outro fenômeno que ocorre no contexto da cibercultura. No que diz respeito às bibliotecas, há alguns estudos importantes a serem destacados: Bernardino, Suaiden, e Cuevas-Cerveró (2014); Calil e Almendra (2016); Lessa e Gomes (2016) e Santos e Almeida (2017).

Tais estudos têm como foco o estudo das mídias sociais, em especial o Facebook, enquanto ferramenta para promoção e apropriação das informações disponíveis nas bibliotecas. Outros estudos se destacam e nos trazem outros elementos conforme apresentamos a seguir.

No que concerne às bibliotecas, Calil (2013) destaca que tem sido crescente a presença destas instituições no ciberespaço e, ainda, a apropriação que elas têm feito das ferramentas da Web 2.0. Ele considera que as mídias sociais e a Web 2.0 "tornam-se categorias cada vez mais nomeadas e conhecidas pelos diversos atores ligados ao universo das unidades de informação" (Calil, 2013, p. 1054).

Essas ferramentas colaborativas permitem que as bibliotecas dialoguem com os usuários de modo que estes não sejam apenas receptores passivos da informação, pois com elas o público também pode criar conteúdo e contribuir para que a biblioteca produza a partir das demandas que são expostas no ambiente dessas redes.

As mídias sociais são utilizadas por diversas instituições com finalidades variadas na produção de conteúdos. No que concerne às bibliotecas, Calil, Corrêa, e Spudeit (2013) argumentam que estas são ambientes que propiciam o compartilhamento de informações e podem obter com esses dispositivos,

um forte aliado na disseminação de seus produtos e serviços, bem como aproveitar seu potencial de alcance para criar um canal de comunicação direta com seus interagentes que vai além de suas limitações de tempo e espaço (Calil et al., 2013, p. 3).

Contudo, nessa dinâmica podem surgir novas responsabilidades a serem desenvolvidas pelas bibliotecas, de modo que, Rezende, Martins, e Silva (2016, p. 485-486) sugerem que: 
Ao mesmo tempo, são esses papéis sociais impensáveis que abrem grandes possibilidades para inovação em produtos e serviços informacionais, permitindo que as próprias bibliotecas produzam novas estratégias de relacionamento e envolvimento social com seus usuários. Um dos aspectos centrais dessas possibilidades de inovação que se pode citar é a mudança cultural provocada pelo incremento no envolvimento dos usuários com esses novos produtos e serviços, ou seja, há aqui a constatação de um maior desejo e potencial de participação social.

Assim sendo, percebe-se que as bibliotecas podem criar laços e papéis sociais para atrair os usuários, assim como desenvolver conteúdos que promovam ações culturais nesse ambiente, desempenhando, assim, a essência das bibliotecas no que se refere à sua missão cultural.

Com os hipertextos nas mídias sociais, as bibliotecas têm a opção de disponibilizar conteúdos que combinem imagens, sons, figuras, e ainda áudios, mostrando-se mais atrativos para estimular o engajamento com o público, promovendo ações que busquem envolver os usuários nesse processo.

Diante das possibilidades que são apresentadas pelas mídias sociais, apesar de o Facebook não ser a única fonte de análise, observa-se que esse meio é oportuno para o estabelecimento de diversas ações entre bibliotecas e o público, pois nele é possível uma interação melhor com os indivíduos pela forma como as postagens são colocadas, diferenciando-se de outras mídias sociais. Nesse sentido, torna-se favorável a publicação de múltiplos conteúdos, no intuito de atrair os usuários a participarem ativamente dos projetos que a biblioteca disponibiliza.

\section{BIBLIOTECAS E AÇÃO CULTURAL}

Para entendermos como se efetivam projetos de ação cultural pelas bibliotecas, é fundamental discutirmos as definições propostas para a ação cultural. De acordo com Teixeira Coelho (2001, p. 33), a essência da ação cultural tem como base a "producao simbolica de um grupo" que implica no movimento em direcao a liberdade de criatividade dos individuos com o intuito de se deslocarem do desconhecido a novas realidades.

O autor pressupõe que na ação cultural é vital o pensamento divergente, agregando ao processo tudo aquilo que interessa sem se preocupar com a origem, já que isso será transformado em pensamento organizado para reestabelecer ou fortificar laços comunitários, a partir de uma ação pautada pela arte operativa como uma de suas principais formas de imaginário.

Nesta acepção, Coelho (2001) caracteriza a ação cultural como um processo cíclico, que precisa ativar três esferas da vida: a imaginação, a consciência refletida a si mesma que inventa e abre possibilidades; a ação, que viabiliza a imaginação; e, por fim, a reflexão, que é a continuidade e exercício teórico, ou seja, a transformação, importando nesta atividade que o sujeito receptor nao seja apenas passivo das acoes recebidas e sim ativo no processo, tornando-se, de fato, um produtor cultural.

Nessa mesma direção, Milanesi (2003) apresenta uma concepção semelhante ao abordar a ação cultural com base no desenvolvimento de atividades que enfoquem as ações informar, discutir e criar. Isto é, um centro de cultura para promover, de fato, projetos de ação cultural deve não apenas disponibilizar o acesso a conteúdos informativos por meios de livros, notícias, apresentações etc. Precisa também promover o debate sobre o conteúdo consumido pelo público, por meio de seminários, fóruns, chats e com isso estimular o pensamento crítico e a formulação de opiniões próprias dos indivíduos.

A última ação, criar, é justamente aquela que proporciona ao indivíduo colocar em prática um conhecimento aprendido, a estimular sua criatividade a inventar, desenvolvendo, inclusive, habilidades antes desconhecidas. Isso tudo é possível em ambientes em que as pessoas se sintam livres para se expressar, sem julgamentos.

Apesar de encontrarmos muitas bibliotecas ainda tradicionais em sua estrutura e serviços, vemos que estas ações são possíveis de serem desenvolvidas em seus ambientes. As bibliotecas públicas, por sua vez, como visam atender as necessidades da comunidade em que estão inseridas, precisam cada vez mais observar essas possibilidades de atuação.

No âmbito informativo, a biblioteca pública deve ir além do empréstimo de livros, oferecendo conteúdos sobre trabalho, emprego, economia, saúde, política, levando assim questões sociais importantes para o dia a dia da comunidade. No âmbito da discussão, deve possibilitar conversas com especialistas sobre estes temas, fóruns, reuniões de tira dúvidas e no contexto criativo ofertar oficinas, aulas práticas, laboratórios, entre outros. Ou seja, promover projetos de ação cultural envolve, de certo modo, esse processo cíclico, tornando o sujeito ativo e não mais um receptor de conteúdos que absorve informações e não sabe como utilizá-las.

Conforme aponta Barros (2010), conhecer a comunidade é um ponto fundamental para a biblioteca pública empreender projetos de ação cultural, pois assim ela se aproxima das características de seu público. A autora corrobora ainda com os três verbos de ação propostos por Milanesi (2003) para a implementação prática de ação cultural em bibliotecas. 
Paulo Freire (2011), ao tratar a ação cultural como um processo para a libertação das classes dominadas frente a uma cultura dominante, argumenta que a ação cultural se estabelece para propiciar aos indivíduos a reflexão crítica sobre si mesmos, emergindo criticamente na realidade para promover transformações sociais.

Percebemos, então, que em vez de indicar um direcionamento, delimitar públicos e áreas de atuação, a ação cultural tem um escopo mais abrangente. Cunha (2010) ressalta que ela envolve projetos que proporcionem justamente a autonomia do processo criativo dos indivíduos, a partir do estabelecimento de atividades que envolvam, entre outros: exposições, debates, seminários, atividades recreativas e de lazer, atividades artísticas e artesanais, cursos e treinamentos.

Contudo, podemos entender a ação cultural como as atividades e projetos desenvolvidos por instituições que colocam o sujeito como parte central do processo. Isto é, possibilita que este tenha acesso a distintas informações, mas que, além disso, proporcione momentos para a reflexão com o intuito de estimular o pensamento crítico e ainda ofereça ambientes propícios ao desenvolvimento prático de atividades como arte, artesanatos, lazer, discussões.

Essas ações fortaleceriam a reflexão sobre valores, o entendimento e o respeito a culturas, a independência de pensamento para tomada de decisão e, até mesmo, proporcionaria melhorias nas condições de vida da comunidade.

\section{SISEB: UMA ANÁLISE DO FACEBOOK}

Nesse tópico, apresentamos as análises das postagens selecionadas. As cinco postagens compreendem o período de 01 de julho à 31 de dezembro de 2017. A utilização da ferramenta netvizz reuniu os dados referentes ao período especificado em uma tabela no Excel, possibilitando que a escolha das pesquisadoras tenha sido mais técnica e objetiva.

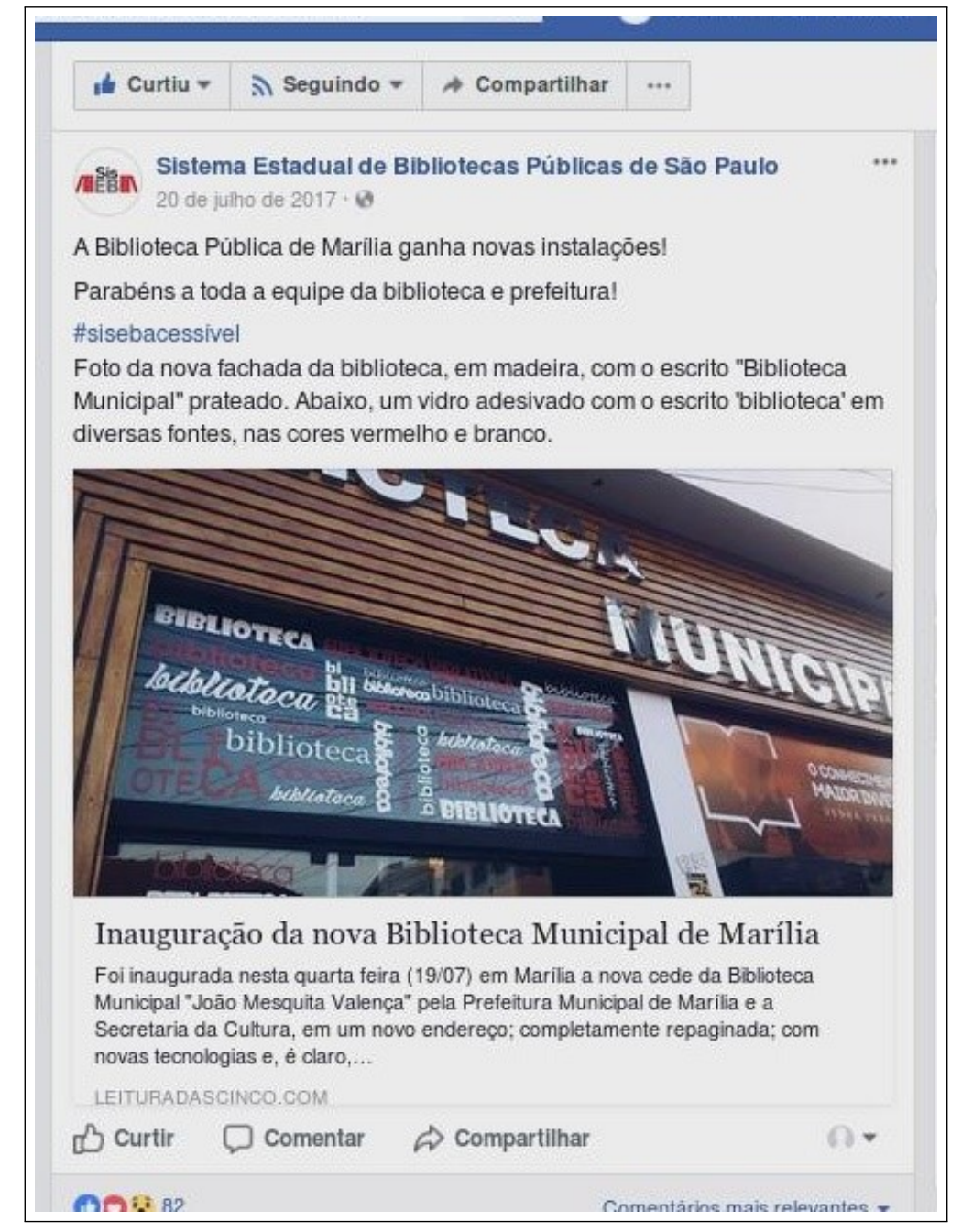

Figura 1. Dia 20 de Julho de 2017.

Fonte: Facebook Sisebsp (2017). 


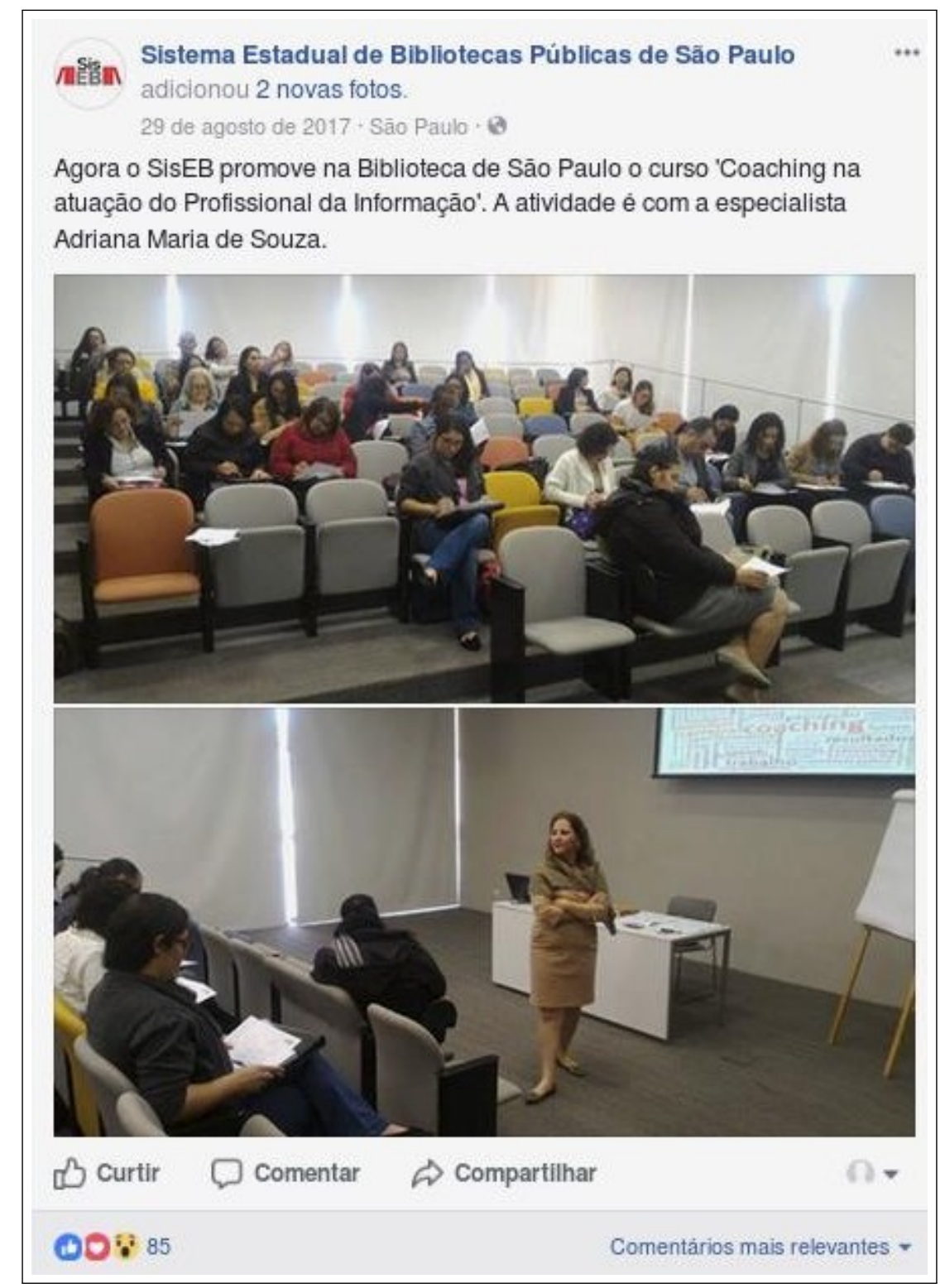

Figura 2. Dia 29 de agosto de 2017.

Fonte: Facebook Sisebsp (2017). 
atit:

Sistema Estadual de Bibliotecas Púbilicas de Săo Paulo

21 de agtembro de $2017=$ a

Oha a dica!

Curso Básco de Formacáo de Contadores de Historas na $B$ blioteca Hans Christian Andersen.

\#sisabacesalvel

Convite nas cores roxo e rosa, no canto interior d reito logo da Prefeltura de Sao Paulo, no canto esquerdo logo do Sistema Municipal de bbliotecas.

Texto resumido: Curso Básico de Fomaçao de Contadores de Historas, minstrado por Kely Cras, Simone Grande, Ana Lusa Lacombe e Wan Magahaes. Incio 30/09 e témino 25/11.

Inscriçoes presencials, de 19/09 a 29/09, na Bblioteca Hans Christ an Andersen. Anexar a ficha uma carta de intença.

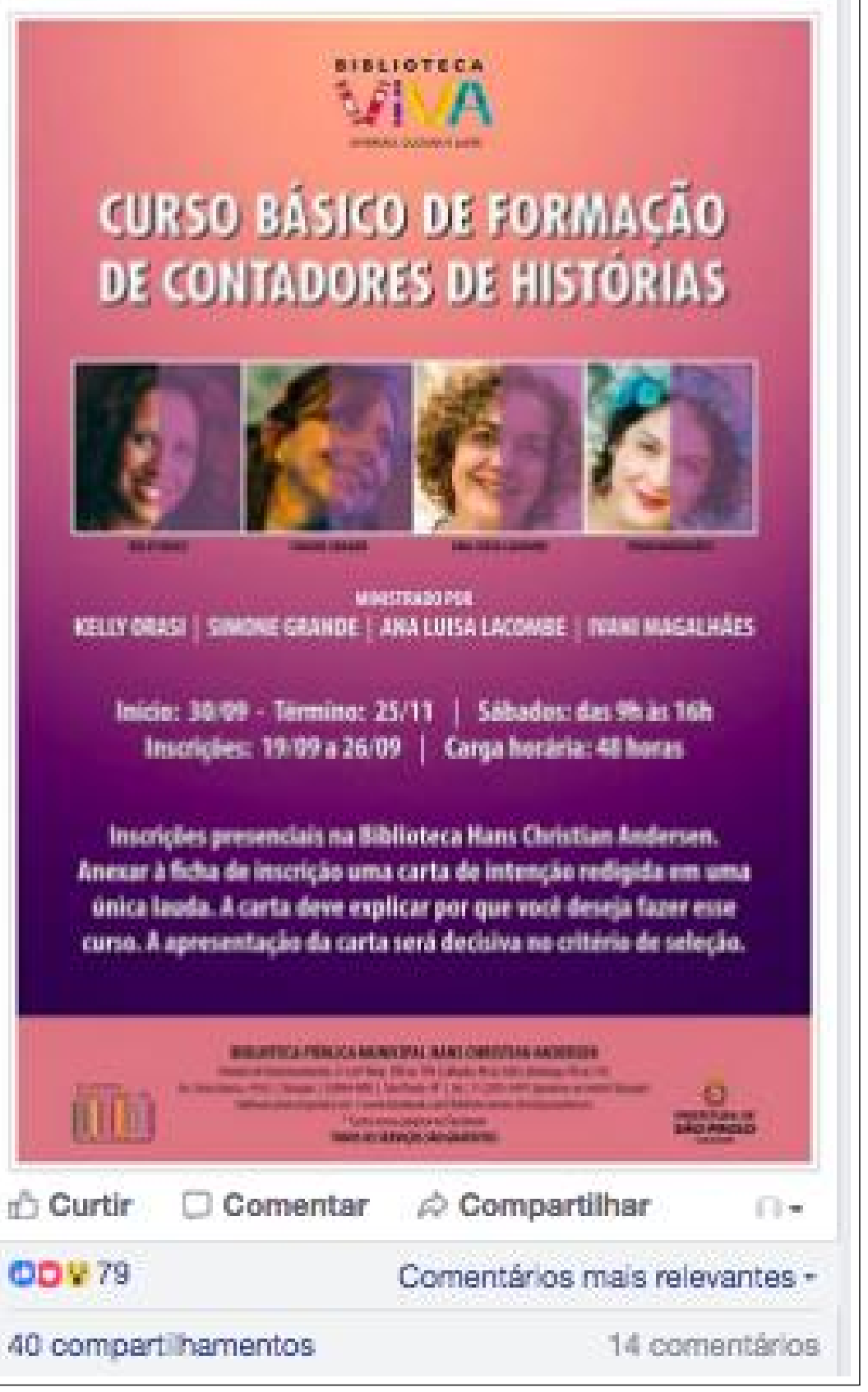


Mftîn Sistema Estadual de Bibliotecas Públicas de Sāo Paulo

Programaçäo imperdivel! Inscriçōes gratuitas!

Gabriele Ceseroglu, da Biblioteca Pública de Colônia - Alemanha, falará sobre a biblioteca como território cultural.

Biblioteque-se!

Dias 23,24 e 25 de outubro.

Local: Centro de Convençöes Rebouças.

Acesse: hitp://bibliotecaviva.org.bri

\#sisebacessivel

Cartaz do $10^{\circ}$ Seminário Bblioteca Viva na cor verde claro, com escritos em preto e branco. No lado esquerdo, a foto da palestrante Gabriele Ceseroglu (Bblioteca Püblica de Colônia - Alemanha) e mediadora Ana Teresa Sannazzaro (Goethe - Institut). No canto inferior direito os logos: SP Leituras, Goethe-Institut São Paulo, SisEB e Governo do Estado de Säo Paulo - Secretaria da Cultura; no canto inferior esquerdo o logo do $10^{\circ}$ Seminário Biblioteca Viva.

Texto resumido: Biblioteque-se 10 anos! Palestra - A biblioteca como território cultural, com Gabriele Ceseroglu e mediaçäo de Ana Teresa Sannazzaro

Local: Centro de Convençōes Rebouças. Dias 23, 24 e 25 de outubro. Inscriçōes gratuitas!

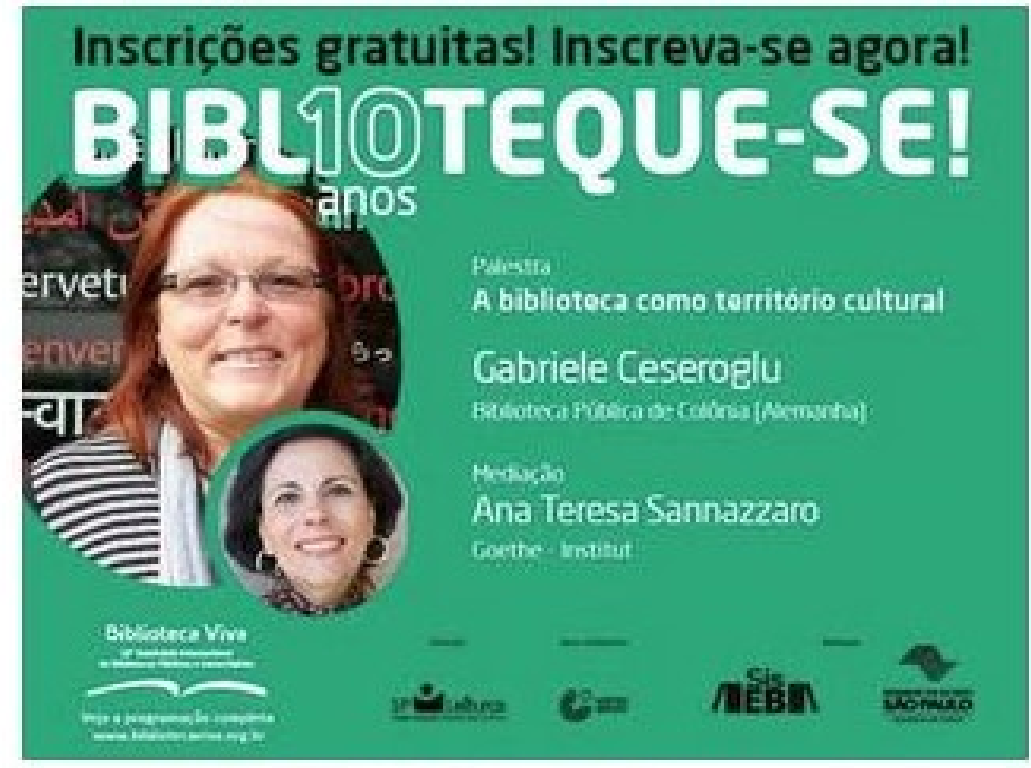

Sistema Estadual de Bibliotecas Públicas de Sāo Paulo

Cadastre-se Organimaço governamenta
13 Curtir
Comentar
$\phi$ Compartilhar

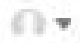

\section{$00 \% 302$}

Figura 4. Dia 11 de outubro de 2017.

Fonte: Facebook Sisebsp (2017). 


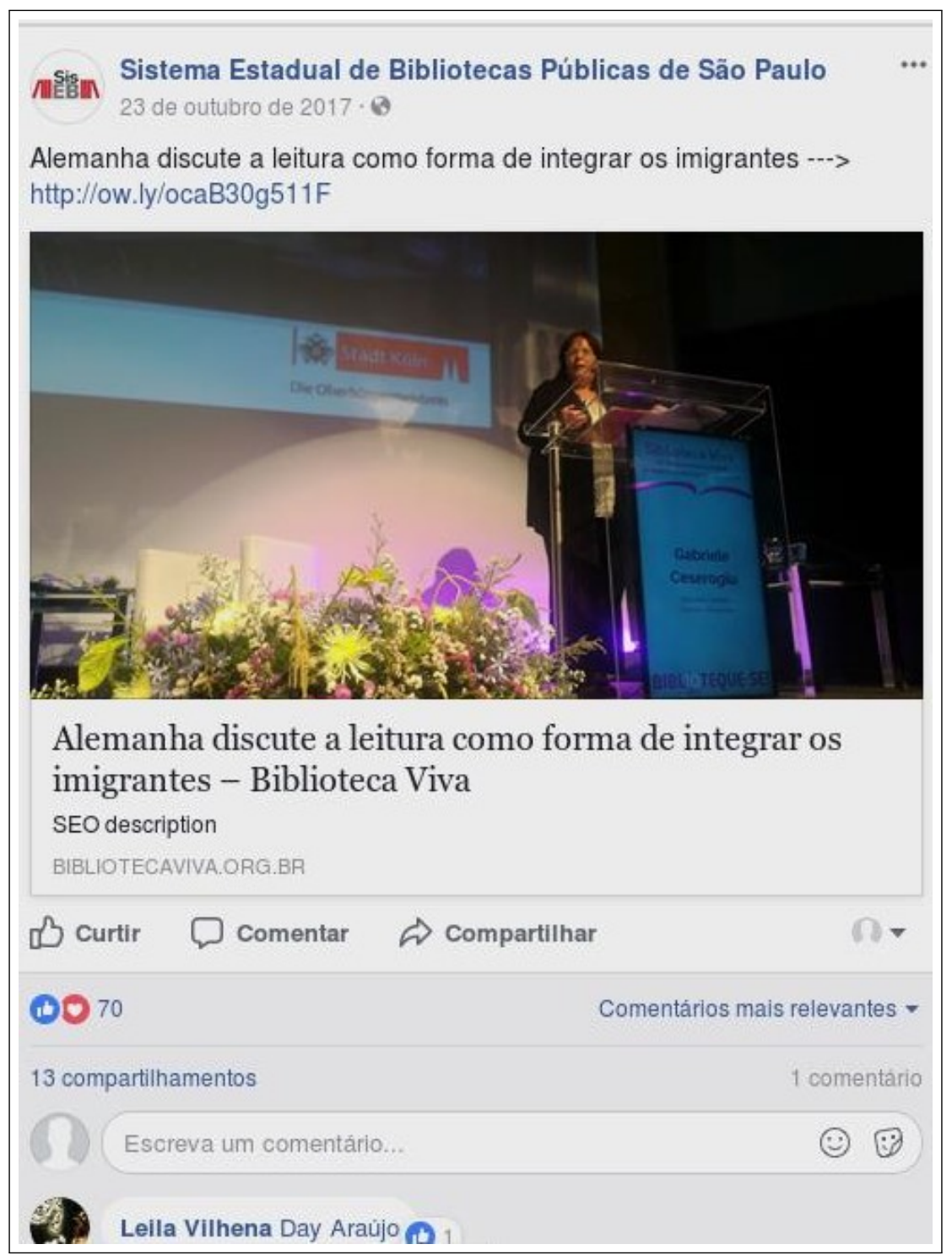

Figura 5. Dia 23 de outubro de 2017.

Fonte: Facebook Sisebsp (2017).

Podemos observar, a partir destas cinco postagens, que os temas das publicações são associados a divulgações sobre notícias, cursos, eventos e programação feitas pela própria rede de bibliotecas. A Figura 1 trata sobre a inauguração de uma nova biblioteca municipal, na qual parabeniza a equipe envolvida no projeto. A Figura 2 informa sobre um novo curso promovido por uma das bibliotecas da rede, ilustrando com algumas fotos de turmas do referido curso, assim como na Figura 3, que também se refere a uma dica de curso, mas agora informa sobre datas e inscrições. Já a Figura 4 fala sobre inscrições para um evento, fazendo uma chamada de ação para que os seguidores façam suas inscrições para aproveitar a programação. Por fim, a Figura 5 trata sobre uma palestra discutida no Seminário Biblioteca Viva, promovido também pelo SisEB.

No próximo tópico, apresentamos a análise de conteúdo em relação a essas postagens trazendo mais elementos a serem discutidos com base no referencial teórico sobre ação cultural.

\section{AÇÃO CULTURAL NAS MÍDIAS SOCIAIS: ANÁLISE DE CONTEÚDO E RESULTADOS}

Neste tópico, realizamos a análise de conteúdo, na qual apresentamos a tabela tematica com a distribuicao dos exemplos extraidos das cinco postagens, encaixando-os nas categorias e informando, ao lado de cada uma, o número de vezes em que se repetem nos posts. Ressalta-se que foram especificados na segunda coluna alguns componentes, relacionados respectivamente as categorias. A inclusao de componentes esta prevista na tabela de (Bardin, 1977) e e utilizada para identificar melhor as categorias que por vezes sao muito abrangentes. Nesse sentido, os componentes explicam os temas abordados nas categorias em uma espécie de subcategorias, conforme Tabela 1. 


\begin{tabular}{|c|c|c|c|}
\hline CATEGORIAS & COMPONENTES & $\begin{array}{l}\text { UNIDADES DE REGISTRO/ } \\
\text { EXEMPLOS }\end{array}$ & FREQ \\
\hline Diversidade social & $\begin{array}{l}\text { Heterogeneidade } \\
\text { Pluralidade } \\
\text { Diferenças } \\
\text { Identidades } \\
\text { Respeito }\end{array}$ & Forma de integrar os imigrantes $(2 x)$ & $4,76 \%$ \\
\hline Cultura & $\begin{array}{l}\text { Instituição cultural } \\
\text { Características sociais } \\
\text { Coletividade } \\
\text { Grupos } \\
\text { Trocas simbólicas }\end{array}$ & $\begin{array}{l}\text { Biblioteca como território cultural (3x) } \\
\text { Secretaria da Cultura }(1 \mathrm{x}) \\
\text { Biblioteca municipal }(4 \mathrm{x}) \\
\text { Sistema municipal de biblioteca }(1 \mathrm{x})\end{array}$ & $\begin{array}{c}21,42 \\
\%\end{array}$ \\
\hline Liberdade & $\begin{array}{l}\text { Expressão } \\
\text { Vontade } \\
\text { Desejo }\end{array}$ & $\begin{array}{l}\text { A carta deve explicar porque você deseja } \\
\text { fazer esse curso (1x) }\end{array}$ & $2,38 \%$ \\
\hline Acessibilidade & $\begin{array}{l}\text { Inclusão social } \\
\text { Pessoas } \\
\text { Singularidade }\end{array}$ & $\begin{array}{l}\text { Inscrições gratuitas }(3 \mathrm{x}) \\
\text { Biblioteca pública }(4 \mathrm{x}) \\
\text { Todos os serviços são gratuitos (1x) }\end{array}$ & $\begin{array}{c}26,19 \\
\%\end{array}$ \\
\hline Criatividade & $\begin{array}{l}\text { Imaginação } \\
\text { Ideias } \\
\text { Criação } \\
\text { Divertimento } \\
\text { Incentivo } \\
\text { Motivação }\end{array}$ & $\begin{array}{l}\text { Seminário Biblioteca Viva (1x) } \\
\text { Parabéns a toda equipe da biblioteca e } \\
\text { prefeitura (1x) } \\
\text { Biblioteca viva ( } 2 x) \\
\text { Olha a dica! (1x) } \\
\text { Diversão, cultura e lazer (1x) }\end{array}$ & $14,3 \%$ \\
\hline $\begin{array}{l}\text { Transformação } \\
\text { social }\end{array}$ & $\begin{array}{l}\text { Ação } \\
\text { Mudanças } \\
\text { Inovação } \\
\text { Progresso }\end{array}$ & $\begin{array}{l}\text { Biblioteque-se! (3x) } \\
\text { Inscreva-se agora! (1x) } \\
\text { Ganha novas instalações (1x) } \\
\text { Inauguração da nova biblioteca (1x) } \\
\text { Agora o SisEB promove na Biblioteca (1x) } \\
\text { Coaching na atuação do Profissional da } \\
\text { Informação (1x) } \\
\text { Alemanha discute a leitura (2x) } \\
\text { Curso Básico de Formação de Contadores } \\
\text { de Histórias (3x) }\end{array}$ & $\begin{array}{c}30,95 \\
\%\end{array}$ \\
\hline \multicolumn{3}{|c|}{ TOTAL } & $100 \%$ \\
\hline
\end{tabular}

Tabela 1. Tabela temática.

Fonte: Tabela elaborada pela autora, conforme a tabela temática de Bardin (1977, p. 74).

De acordo com as categorias estipuladas na tabela, foi possível exemplificar o total (42) unidades de registro que correspondem ao quantitativo final de itens, os quais apresentam os seguintes resultados: a categoria com mais unidades de registros foi "Transformação social", que corresponde à 30,95\% do total, compreendendo 13 itens.

A categoria "Liberdade" teve apenas uma unidade como exemplo, correspondendo à $2,38 \%$ do total. Nem todas as palavras contidas nas publicações se encaixaram em alguma categoria. No entanto, nenhuma categoria ficou vazia, o que nos revelou, inicialmente, alguns indícios importantes para a análise, os quais estão descritos nas unidades de registros da Tabela 1.

No que refere-se à categoria "Transformação social", que indica mudanças, inovação e progresso social, conforme os conceitos de ação cultural expostos acima, os exemplos que se encaixaram nela representam ações, como: "Biblioteque-se!" e "Inscreva-se agora!", que se constituem com verbos no imperativo para estimular, de alguma maneira, os indivíduos a agirem a partir disso.

Os exemplos "Coaching na atuação do Profissional da Informação" e "Curso Básico de Formação de Contadores de Histórias" pressupõem aprendizado e formação profissional, ou seja, indicam mudanças e evolução em áreas de atuação, contribuindo para o progresso pessoal dos participantes do curso.

Esses serviços, quando da coleta de dados, seriam ainda ofertados pelo SisEB e destacam-se por serem distintos dos serviços tradicionais já disponibilizados pelas bibliotecas. Enfatiza-se que, além de apenas publicizar estas informações, o Sistema oferece o espaço para que esta ação seja concretizada e que, inclusive, são disponibilizadas de forma gratuita e acessível a todos conforme observamos na Tabela 1, na categoria "Acessibilidade", com as unidades de registro "Inscrição gratuita", que se repetem três vezes na publicação da Figura 4, bem como em "Todos os serviços são gratuitos", que apareceu uma vez na unidade de registro referente à postagem da Figura 3. 
A categoria "Diversidade social", apesar de ter recebido apenas um exemplo como unidade de registro, destacase por representar uma importante questão social discutida nos últimos anos, devido à crise dos refugiados com a Guerra na Síria ${ }^{3}$. O exemplo da postagem da Figura 5, divulga uma ação que ocorreu na Alemanha que visa integrar os imigrantes, a partir da leitura, atividade esta que é uma das principais missões das bibliotecas as quais devem ter espaços propícios para dar acesso e ações de incentivo à leitura na comunidade.

Na categoria "Criatividade", correspondente a seis exemplos, observam-se evidências de ações que estimulam a criação e a imaginação. No exemplo "Parabéns a toda a equipe da biblioteca e prefeitura", acerca da postagem da Figura 1, o SisEB faz um elogio aos envolvidos na reforma da Biblioteca Pública de Marília que, após ganhar novas instalações, ampliará seus serviços e atendimento à demanda de seus usuários. Em "Olha a dica!", a Instituição utiliza uma linguagem menos formal, interessante para dialogar com jovens e chamar atenção para o texto em seguida, o qual trata-se de um curso gratuito oferecido pelas bibliotecas do SisEB.

É importante destacar ainda que, das cinco postagens, três delas utilizaram a hashtag sisebacessível, baseando-se no projeto PraCegoVer, visando a disseminação da cultura da acessibilidade nas redes sociais, por meio do recurso de áudio descrição das postagens, tornando as imagens publicadas acessíveis e "legíveis" a cegos, pessoas com baixa visão, com dislexia, deficiência intelectual, entre outras. O recurso tem sido utilizado por diversas instituições, marcas e pessoas nas mídias sociais para integrar pessoas com necessidades especiais. Nesse sentido, observa-se o cuidado do SisEB em promover e disseminar também essa cultura.

Todas as categorias aqui estabelecidas como proprias da acao cultural foram contempladas com alguma unidade de registro, sendo que os exemplos categorizados se aproximam da promoção de ações culturais, conforme propõem Milanesi (2003) e Barros (2010), pois os temas são relacionados aos exemplos citados pelos autores como possibilidades de se promoverem projetos culturais, tais como: seminários, palestras e cursos.

Alguns temas abordados nos cursos e palestras divulgados por meio das postagens analisadas tratam sobre temáticas sociais importantes, como a biblioteca enquanto território cultural e integração dos imigrantes, o que fomenta a formação de opiniões dos indivíduos, proporcionando contato com outras realidades e promovendo o respeito a outras culturas que são pilares dos objetivos da ação cultural.

No entanto, observa-se que as publicações analisadas possuem caráter mais de divulgação, referindo-se às atividades realizadas nos ambientes físicos das bibliotecas do SisEB, fazendo chamada para inscrição e participação, não havendo a promoção de debates junto ao próprio conteúdo publicado no Facebook. Conforme exposto por Milanesi (2003) e Barros (2010), esse seria um dos cernes da ação cultural: a promoção de debates sobre os temas para provocar o pensamento crítico dos indivíduos e não apenas o acesso às informações.

Fazer essa ação acontecer no indivíduo é o que o torna ativo no processo de transformação, conforme proposto por Coelho (2001); então a biblioteca poderia utilizar o Facebook para fazer perguntas nas legendas e promover debates por meio das respostas nos comentários, poderia fazer concursos culturais por meio de postagens, promover lives, sorteios e assim explorar outras funcionalidades que a plataforma disponibiliza para fazer a ação cultural acontecer também nesse ambiente online.

Conforme foi analisado, podemos considerar como primeiras inferências que as publicações do SisEB possuem relacao com projetos e conceitos referente às acoes culturais, mas a maioria é relacionada aos projetos que ocorrem em seus espaços físicos. Porem, essas sao apenas impressoes preliminares, ja que é necessário ampliar a análise para outras postagens, com uma amostra maior, efetuando uma análise mais profunda para verificar com mais evidencias a existencia das tres esferas que Coelho (2001) define como proprias da acao cultural: a imaginacao, a acao e a reflexao que levam a transformacao dos indivíduos.

Como durante a revisão desse trabalho estamos em meio à Pandemia da Covid-19, seria relevante uma outra pesquisa a fim de analisar as atividades virtuais promovidas durante o isolamento social. Nesse caso, tal estudo poderia revelar ações culturais para além dos resultados aqui alcançados.

\section{CONSIDERAÇÕES FINAIS}

Diante dos dados obtidos por meio da fundamentação teórica e da análise de conteúdo, observamos que as mídias sociais são potenciais aliadas para o desenvolvimento de diversas atividades das bibliotecas. O Facebook é uma tecnologia disponível à sociedade, que só será efetiva em projetos culturais por meio do engajamento ativo, o qual deve ser feito tanto pelas instituições, ali representadas pela página da rede social da biblioteca, quanto pelo público, representado pelos seguidores da página.

Há de se considerar o fenômeno da bolha, uma vez que os algoritmos das mídias sociais tendem a fechar o campo de visão do usuário, "mostrando" informações que não condizem com todas possibilidades possíveis na rede. Há

\footnotetext{
${ }^{3}$ Em busca de segurança, de 6,3 milhões de sírios estão deslocadas dentro do país e outros 5 milhões de refugiados da Síria estão no exterior, muitos em campos de refugiados. Muitas pessoas que haviam se mudado para a Síria fugindo de conflitos em Estados vizinhos hoje são novamente afetados pela violência. A imigração Síria é hoje um dos maiores movimentos de pessoas no mundo. Recuperado de: https://www.icrc.org/pt/pessoas-refugiadas-da-siria (2020, novembro 6)
} 
aí a necessidade de um trabalho que motive as competências informacionais dos usuários para que esses possam "enxergar" além daquilo que é mostrado.

Retomando a pergunta central que conduziu este trabalho, qual seja: como as postagens no Facebook do Sistema Estadual de Bibliotecas Públicas de São Paulo (SisEB) realizam promoção de ação cultural junto aos seguidores?, chegamos à seguinte resposta após as discussões e análises realizadas: o conteúdo das postagens do Facebook têm relação com assuntos relacionados à promoção de ações culturais, no entanto, elas são focadas mais na divulgação das atividades presenciais das bibliotecas do SisEB do que no desenvolvimento de ações diretamente na plataforma do Facebook.

Vimos a representatividade que o SisEB possui no ambiente em que está integrado; a quantidade de pessoas que segue essa rede e que a partir dela produzem sentidos às mensagens que são compartilhadas; por fim, a reputação e o poder para influenciar o público, são pontos essenciais para a efetividade de ações, tais como as culturais desenvolvidas por essa Rede de Bibliotecas.

Nesse sentido, cabe mencionarmos que o fio condutor para a efetividade de ações nas mídias sociais são as motivações e afinidades entre o público ali envolvido, as quais possibilitam que ocorram as interações, as trocas simbólicas e a geração de valor aos grupos.

As bibliotecas, por serem organismos em constante crescimento, devem estar atentas às inovações da sociedade, acompanhando esse processo para estarem sempre próximas do seu público, buscando, sobremaneira, criar serviços e produtos informacionais a fim de satisfazer os anseios de seus usuários.

Contudo, depreende-se que as mídias sociais aproximam o contato entre bibliotecas e usuários, pois, conforme verificamos nas postagens selecionadas para a análise, há curtidas, comentários e compartilhamentos das notícias publicadas, apresentando indícios sobre o interesse que o público possui nessa Rede. No processo de ação cultural, portanto, é primordial a iniciativa das bibliotecas no desenvolvimento de conteúdos sobre o assunto no Facebook, disponibilizando os espaços para que essas ações ocorram e, ainda, o estimulando o engajamento dos seguidores dessas páginas. A partir disso, poderão desenvolver projetos diversos para estabelecer ações culturais que beneficiem, de algum modo, tanto o desenvolvimento individual, como o de grupos. 


\section{REFERÊNCIAS}

Bardin, L. (1977). Análise de conteúdo. Lisboa: Edições 70 .

Barros, M. H. T. C. (2010). Ação cultural em bibliotecas públicas e escolares. Infohome. Recuperado de https:// www.ofaj.com.br/colunas conteudo.php? $\operatorname{cod}=533$

Bernardino, M. C. R., Suaiden, E. J., \& Cuevas-Cerveró, A. (2014). O uso do facebook pelas bibliotecas públicas do estado do ceará. InCID: Revista de Ciência da Informação e Documentação, 5(1), 112-123.

Calil, A. J. (2013). Mídias sociais nas bibliotecas universitárias brasileiras. Revista ACB: Biblioteconomia em Santa Catarina, 18(2), 1053-1077. Recuperado de https:// revista.acbsc.org.br/racb/article/view/899

Calil, A. J., \& Almendra, G. (2016). As apropriações do facebook pelas bibliotecas públicas estaduais brasileiras. Em Questão, 22(1), 188-213.

Calil, A. J., Corrêa, E. C. D., \& Spudeit, D. (2013). O uso das mídias sociais nas bibliotecas brasileiras: análise dos trabalhos apresentados no snbu e cbbd. In Anais do congresso brasileiro de biblioteconomia, documentação e ciência da informação-febab (v. 25, p. 5044-5059). Florianǿpolis, SC, Brasil. Recuperado de https://portal.febab.org.br/anais/ article/viewFile/1634/1635

Castells, M. (2010). A sociedade em rede (7a. ed., v. 1). São Paulo: Paz e Terra.

Coelho, T. (2001). O que é ação cultural. São Paulo: Brasiliense.

Cunha, N. (2010). Cultura e ação cultural: uma contribuição a sua histǿria e conceitos. São Paulo: Edições SESC.

Freire, P. (2011). Ação cultural: Para a liberdade e outros escritos (14a. ed.). Rio de Janeiro: Editora Paz e Terra.

Lemos, A. (2013). Cibercultura: tecnologia e vida social na cultura contemporânea (6a. ed.). Porto Alegre: Sulina.

Lessa, B. B. L., \& Gomes, H. F. (2016). Bibliotecas públicas do brasil e o uso de dispositivos de comunicação da web social: o facebook como espaço de mediação da informação. In Anais do encontro nacional de pesquisa em ciência da informação (enancib) (v. 17). João Pessoa, PB. Recuperado de http://www.ufpb.br/evento/index.php/ enancib2016/enancib2016/paper/viewFile/3645/2292

Levy, P. (2010). Cibercultura. São Paulo: Editora 34.

Lévy, P., \& Lemos, A. (2010). O futuro da internet: em direção a uma ciberdemocracia planetária. São Paulo: Paulus.

Mainieri, T. (2016). Um peso, duas medidas: desvelando a comunicação pública na sociedade midiatizada. Goiânia: FIC/UFG.

Milanesi, L. (2003). Centro de ação cultural. In A casa da invenção (4a. ed.). São Paulo: Ateliê Editorial.

Recuero, R. (2010). Mídia x rede social. Blog. Recuperado de http://www.raquelrecuero.com/arquivos/2010/11/midia -x-rede-so.html

Rezende, L. V. R., Martins, D. L., \& Silva, M. F. (2016). Mídias sociais em tempos de bibliotecas 2.0: um estudo em bibliotecas das instituições federais de ensino brasileiras trazendo perspectivas futuras para a preservação digital. RDBCI: Revista Digital de Biblioteconomia e Ciência da Informação, 14(3), 484-500.
Sanatella, L. (2003). Culturas e artes do pós-humano: da cultura das mídias à cibercultura. São Paulo: Paulus.

Santos, J. A., \& Almeida, O. F. J. (2017). Bibliotecas universitárias das instituições estaduais de ensino superior paranaenses e a mediação da informação no facebook. $R D B C I$ : Revista Digital de Biblioteconomia e Ciência da Informação, 15(2), 442-468.

Sistema Estadual de Bibliotecas Públicas de São Paulo. (2018). Blog. Recuperado de https://www.facebook.com/ sisebsp/

Telles, A. (2011). A revolução das mídias sociais (2a. ed.). São Paulo: M. Books.

Como citar este artigo (APA):

Santos, A. P. \& Nascimento, V. G. (2021). Ação cultural com mídias sociais: análise do Facebook do Sistema Estadual de Bibliotecas Públicas de São Paulo (SisEB). AtoZ: novas práticas em informação e conhecimento, 10(1), 25 - 38. Recuperado de: http:// dx.doi.org/10.5380/atoz.v10i1.76615 